\title{
Radiochemotherapy for Brain Metastasis: How to Define a Role for Temozolomide
}

\author{
Michael Weller \\ Department of General Neurology, Center for Neurology, University of Tübingen Medical School, Germany
}

The positive results of the EORTC 26981-22981 NCIC CE.3 trial of concomitant and adjuvant temozolomide added to involved-field radiotherapy in newly diagnosed glioblastoma [1] have revived the interest in exploring similar treatment strategies in patients with metastatic brain disease. In addition to various single-arm trials reported within the last 5 years, 2 randomized phase II trials have already examined the possible benefit of temozolomide added to radiotherapy in patients with brain metastases. The first trial enrolled largely patients with lung and breast cancer and reported an increase in the response rate from 67 to $96 \%$ in the experimental group and a moderate reduction in the percentage of steroid-dependent patients at 2 months after radiotherapy, although survival was unaffected [2]. However, this trial has remained controversial because such a high response rate has never been reproduced in any other series. The second trial focused on malignant melanoma and observed no change in the response rate or in overall survival, but a decrease in death from brain metastases from 69 to $41 \%$ [3]. None of these trials demonstrated a survival benefit.

In this issue of ONKOLOGIE, Kouvaris and colleagues [4] report the results of a phase II study of temozolomide (60 $\mathrm{mg} / \mathrm{m}^{2} / \mathrm{d}$, days $\left.1-18\right)$ added to whole-brain radiotherapy $(13 \times 3$ Gy administered over 18 days $)$ followed by adjuvant temozolomide $\left(200 \mathrm{mg} / \mathrm{m}^{2} / \mathrm{d}\right.$, days $1-5, \times 28$ days $)$ in 33 patients with cerebral metastases from small cell lung cancer $(\mathrm{n}=4)$, non-small cell lung cancer $(\mathrm{n}=10)$, breast cancer $(\mathrm{n}=7)$, rectal cancer and malignant melanoma $(\mathrm{n}=5$ each $)$, and oral and unkown origin $(\mathrm{n}=1$ each). 9 patients had single metastases, but were still not considered candidates for surgical resection. All patients were reported to have stable systemic disease. The objective response rate was 54.5 and $57.6 \%$ after the third and the sixth cycle in all patients and $78.6 \%$ in patients with lung cancer. The median overall survival was 12 months. The most common side effects were ane- mia $(24.2 \%)$, thrombocytopenia $(18.2 \%)$ and nausea and vomiting $(18.2 \%)$. The high incidence of hepatotoxicity $(45.5 \%)$ was attributed to antiepileptic drugs rather than temozolomide. While this series confirms and extends the notion that the addition of chemotherapy to whole-brain radiotherapy may improve local control in the brain, a pivotal trial demonstrating the efficacy of this approach has not even been designed.

The difficulties in interpreting the results from this and various other trials appear to call for changing paradigms in the design of clinical trials for the treatment of patients with brain metastases. Given that brain metastasis is not an uncommon condition and that we would never pool patients with metastatic disease in a specific site other than brain from various types of primary cancers, why should we continue to do so in metastasis to the brain? Further, recursive partitioning analyses have already shown how variable the course of metastatic brain disease is, depending on age, Karnofsky performance score and control of systemic disease [5]. This calls for narrowing the inclusion criteria and thereby homogenizing the clinical condition of patients enrolled in each clinical trial. Also, depending on the design of the trial, it is important to carefully define the clinical or radiological endpoints. The rationale of using concomitant treatment with temozolomide in addition to radiotherapy is usually to enhance local control in the brain, mediated by a radiosensitizing effect. The role, if any, of adjuvant temozolomide in that setting is unclear. The chances of translating improved local control into a gain in survival are best when patients are selected not to require further systemic treatment, which may modify both local and systemic endpoints, at least in the near feature. Even with systemic treatment, a significant number of patients with brain metastases die from systemic tumor progression and not from their brain metastases. Whether there is truly a rationale for adjuvant temozolomide in such trials, needs probably to be

\begin{tabular}{llll}
\hline KARGER & ( 2007 S. Karger GmbH, Freiburg & & $\begin{array}{l}\text { Prof. Dr. Michael Weller } \\
\text { Universität Tübingen }\end{array}$ \\
Fax +49 7614 520714 & Accessible online at: & Allgemeine Neurologie, Neurologische Klinik \\
$\begin{array}{l}\text { E-mail Information@Karger.de } \\
\text { www.karger.com }\end{array}$ & www.karger.com/onk & Hoppe-Seyler-Straße 3, 72076 Tübingen, Germany \\
& & Tel. +49 7071 29-82049, Fax -5260 \\
& & E-mail michael.weller@uni-tuebingen.de
\end{tabular}


defined for each single type of primary tumor. Depending on the intrinsic sensitivity of each tumor entity to temozolomide, adjuvant treatment may or may not modify systemic endpoints as well. The same considerations apply to similar ap- proaches using other agents such as topotecan [6] which may exert both radiosensitizing effects as well as intrinsic antitumor activity.

\section{References}

1 Stupp R, Mason WP, van den Bent MJ, Weller M, Fisher B, Taphoorn MJB, Belanger K, Brandes AA, Cairncross JG, Marosi C, Bogdahn U, Curschmann J, Janzer RC, Ludwin S, Gorlia T, Allgeier A, Lacombe D, Eisenhauer E, Mirimanoff RO, on behalf of the European Organisation for Research and Treatment of Cancer (EORTC) Brain Tumor and Radiotherapy Groups and National Cancer Institute of Canada Clinical Trials Group (NCIC CTG) Radiotherapy plus concomitant and adjuvant temozolomide for patients with newly diagnosed glioblastoma. N Engl J Med 2005;352:987-996.
2 Antonadou D, Paraskevaidis M, Sarris G, Coliarakis N, Economou I, Karageorgis P, Throuvalas $\mathrm{N}$ : Phase II randomized trial of temozolomide and concurrent radiotherapy in patients with brain metastases. J Clin Oncol 2002;20:3644-3650.

3 Verger E, Gil M, Yaya R, Vinolas N, Villa S, Pujol T, Quinto L, Graus F: Temozolomide and concomitant whole brain radiotherapy in patients with brain metastases: a phase II randomized trial. Int J Radiat Oncol Biol Phys 2005;61:185-191.

4 Kouvaris JR, Miliadou A, Kouloulias VE, Kolokouris D, Balafouta $\mathrm{MH}$, Papacharalampous XN, Vlahos LJ: Phase II study of temozolomide and concomitant whole-brain radiotherapy in patients with brain metastases from solid tumors. Onkologie 30; DOI: $10.1159 / 000102557$.
5 Gaspar LE, Scott C, Murray K, Curran W: Validation of the RTOG recursive partitioning analysis (RPA) classification for brain metastases. Int J Radiat Oncol Biol Phys 2000;47:1001-1006.

6 Hedde JP, Neuhaus T, Schüller H, Metzler U, Schmidt-Wolf IG, Kleinschmidt R, Losem C, Lange O, Grohe C, Stier S, Ko YD: A phase I/II trial of topotecan and radiation therapy for brain metastases in patients with solid tumors. Int J Radiat Oncol Biol Phys 2007 in press. 